\title{
Review Article \\ Systematic Modeling of Impacts of Land Use and Land Cover Changes on Regional Climate: A Review
}

\author{
Xiangzheng Deng, ${ }^{1,2}$ Chunhong Zhao, ${ }^{1,2,3}$ and Haiming Yan ${ }^{4}$ \\ ${ }^{1}$ Institute of Geographic and Natural Resources Research, Chinese Academy of Sciences, Beijing 100101, China \\ ${ }^{2}$ Center for Chinese Agricultural Policy, Chinese Academy of Sciences, Beijing 100101, China \\ ${ }^{3}$ University of Chinese Academy of Sciences, Beijing 100049, China \\ ${ }^{4}$ State Key Laboratory of Water Environment Simulation, School of Environment, Beijing Normal University, Beijing 100875, China
}

Correspondence should be addressed to Xiangzheng Deng; dengxz.ccap@igsnrr.ac.cn

Received 23 May 2013; Accepted 2 July 2013

Academic Editor: Hongbo Su

Copyright (C) 2013 Xiangzheng Deng et al. This is an open access article distributed under the Creative Commons Attribution License, which permits unrestricted use, distribution, and reproduction in any medium, provided the original work is properly cited.

There have been tremendous changes in the global land use pattern in the past 50 years, which has directly or indirectly exerted significant influence on the global climate change. Quantitative analysis for the impacts of land use and land cover changes (LUCC) on surface climate is one of the core scientific issues to quantitatively analyze the impacts of LUCC on the climate so as to scientifically understand the influence of human activities on the climate change. This paper comprehensively analyzed the primary scientific issues about the impacts of LUCC on the regional climate and reviewed the progress in relevant researches. Firstly, it introduced the influence mechanism of LUCC on the regional climate and reviewed the progress in the researches on the biogeophysical process and biogeochemical process. Then the model simulation of effects of LUCC on the regional climate was introduced, and the development from the global climate model to the regional climate model and the integration of the improved land surface model and the regional climate model were reviewed in detail. Finally, this paper discussed the application of the regional climate models in the development and management of agricultural land and urban land.

\section{Introduction}

The land use and cover changes (LUCC), in which the human activities play a dominant role, interact with the environment and have significant effects on the ecosystems at the local, regional, and global scales and consequently directly or indirectly exert great influence on the global climate changes [1-4]. People have come to realize that the global change always consists of a series of regional changes with various processes and patterns according to the more and more observations [5]. On the one hand, the initial regional change will gradually extend to the interregional and even larger scales and consequently influence the change of the global environment. So it is necessary to first take into account the local and regional climatic effects in the research on the effects of the LUCC on the climate. On the other hand, since there is a great difference in the physical, chemical, and biological characteristics of the land surface in different regions on the Earth, the impacts of the land use and land cover changes on the regional climate systems also vary greatly. For example, the deforestation may lead to the temperature increase in the tropic zone, while it may lead to the regional temperature decrease in the frigid zone [6]. Therefore, in order to completely reflect the relationship between LUCC and the climatic factors, it is necessary to carry out and make comparisons among a lot of case studies in different regions and at various spatiotemporal scales and analyze the spatiotemporal processes and land surface parameters of the LUCC and the response of the climate. However, there have been very few relevant researches.

It has long been known that the land use changes caused by human activities such as deforestation and agriculture practice have some effects on the climate $[1,7]$. The land use changes can influence climate by changing the properties of the land surface which is not only the direct heat source of the troposphere, but also one of the main sources of 
the atmospheric vapor water [8]. Therefore, the change in the characteristics of the land surface will directly influence the land surface-atmosphere interaction and consequently alter the thermodynamic and dynamic characteristics of the atmosphere and finally lead to different climate processes and patterns [9]. The land use activities have significantly changed the regional land cover, thus leading to climate changes. For example, the deforestation [10], afforestation [11], agriculture practice [7], and urbanization [12, 13] all influence the energy budget and Bowen ratio of the land surface, the distribution of the precipitation among the soil water, runoff, and evapotranspiration. The land use activities also have important influence on the characteristics of regional climate system, for example, the temperature, evapotranspiration, precipitation, wind field, atmospheric pressure, and especially the temperature and precipitation [14-16]. In addition, the recent researches suggest that the LUCC may affect the extremes in temperature $[2,17]$ and precipitation $[18]$.

The LUCC affects the local, regional, and global climate systems through various biogeochemical and biogeophysical processes $[15,19,20]$. For example, the biogeochemical process can indirectly affect the climate by altering the rate of the biogeochemical cycle and thereby changing the chemical composition of the atmosphere [21]. Besides, it may also affect the climate through the absorption or emission of greenhouse gases [21]. By contrast, the biogeophysical process directly affects the physical parameters that determine the absorption and disposition of energy at the land surface [15]. For example, it influences albedo or reflective properties of the land surface [22], alters the absorption rate of solar radiation, and hence influences the energy availability at the land surface [23]. In addition, the surface hydrology and vegetation transpiration characteristics also affect how the energy received by the surface is distributed into the latent and sensible heat fluxes [4]. The vegetation structure can affect the surface roughness and thereby alter the momentum and heat transport.

Owing to the limitation of knowledge and lack of interdisciplinary cooperation, there is still lack of full understanding of the mechanism of the procedures of the climate process and how the land use changes influence the regional climate and consequently influence the global climate [4]. There are separate studies of the biogeochemical and biogeophysical effects of the land use changes on the climate in their respective fields, and there are few researches on their joint effects on the climate. However, there are still a lot of uncertainties in the current knowledge, and it is still very difficult to objectively assess the contribution of the land use changes to the climate change [15]. For example, Hansen et al. [24] proposed that the radiative forcing due to the change in albedo caused by the global land use changes may decrease the temperature. By contrast, Intergovernmental Panel on Climate Change (IPCC) believed that the increase of $\mathrm{CO}_{2}$ in the atmosphere will reinforce the radiative forcing, $1 / 3$ of which was contributed by the land use changes, and consequently increase the temperature [2]. So it is of great importance to objectively analyze the biogeochemical and biogeophysical effects of the land use changes on the climate [1]. It is necessary to carry out further researches on the development of more accurate monitoring and modeling methods, which are essential to the understanding of these interactions and feedbacks [25]. However, the major challenge is how to integrate the researches on the biogeophysical and biogeochemical processes.

The impacts of land use changes on the climate are the synthetic effects of the biogeophysical process and biogeochemical process. But which of the two kinds of processes makes a greater contribution to the climate change at the regional scale, or which one plays a dominant role? The climate model is an effective tool in the study of climate, but how should it be applied to the research on the regional effects of LUCC? What effects will the improvement of the regional climate model have on the LUCC simulation? This paper reviewed the history and methods of the relevant researches, and summarized the influence of LUCC on the regional climate system and the simulation strategies according to the researches in the recent decades. Finally, the application of the regional climate models in the development and management of agricultural land and urban land was discussed.

\section{Mechanism Research on the Influence of LUCC on the Regional Climate}

The research on the influence of the land use changes on the regional temperature and precipitation can be dated back to the 1970s. The land use changes can alter various physical characteristics of the land surface, including the land surface parameters such as albedo [22], upward long-wave radiation, and roughness and the vegetation parameters such as the vegetation coverage and leaf area index (LAI) [26]. All the changes in these parameters can influence the energy budget and water budget through the land-surface process, have an effect on the atmospheric boundary layer, and further impact the free air [27]. So it can be said that the changes in the parameters of the land surface and vegetation are the fundamental reason for the effects of the land use changes on the atmosphere [28]. By the 1980s, the researchers realized that the land use influences the climate not only through the change in physical characteristics of the land surface, but also through the greenhouse emission. Thereafter, there were more and more researches on the effects of land use on the carbon cycle. The influence of the land use changes on the climate involves not only the biogeophysical process, but also the biogeochemical process [20].

2.1. Studies on Influence of Physical Characteristics on the Climate. Charney et al. [29] first explored the relationship between the change of albedo and the drought in the Sahara region. Thereafter, there were a lot of researches on the influence on the regional climate (e.g., temperature and precipitation), which is exerted by the single parameter of physical characteristics of the land surface (e.g., albedo, roughness, leaf area index, and soil moisture) [30, 31]. The change in the underlying landscape alters the energy and moisture budgets of the land surface at the regional scale, which in turn leads to the changes in the fluxes of heat, water, and dynamics of the near-surface atmosphere and influences 
the key thermodynamic and dynamic properties of the air, which is of great importance to the air convection [32]. The evidence to support this statement comes from the sensitivity studies that explore the impacts of the change on the characteristics of land surface $[33,34]$.

There is considerable evidence of the significance of land surface processes generated through regional-scale perturbation experiments and researches on the deforestation $[6$, $35,36]$, desertification [37, 38], and land use changes [4, 39]. These researches all indicated the LUCC contributed to the large and statistically significant change in the temperature, rainfall, and other variables at the continental or regional scales.

First and foremost, some important researches on the sensitivity of climate to the change of land surface evapotranspiration were performed by Claussen et al. [40] and Davin and de Noblet-Ducoudre [41], which provided significant evidence that the change of the land surface evapotranspiration can lead to great changes in the temperature and precipitation. For example, the deforestation will lead to the decrease of evapotranspiration [39], while the decrease of latent heat will increase the near-surface temperature and lead to higher sensible heat flux [41]. There is a high transpiration rate in the tropic rainforest, where the decrease of the transpiration rate due to the disappearance of the tropic rainforest may lead to regional warming and drought in the future $[4,42]$. In addition, the change in evapotranspiration also influences the water content in the atmosphere and reduces the greenhouse effect and consequently reduces the temperature [34], while the decrease of the cloud covers will increase the solar radiation and consequently strengthen the temperature [43]. Therefore, due to the large number of parameters, it is difficult to quantitatively compare the two feedbacks and there is great uncertainty [2].

The land surface albedo is the fraction of solar energy (shortwave radiation) reflected from the land surface into space. It represents the reflecting power of the land surface and plays a key role in influencing the radiation balance and energy balance of the land surface [44]. The change in the land surface albedo directly alters the solar radiation absorbed by the land surface, subsequently leads to the change in the long-wave radiation of the land surface into space and the sensible heat and latent heat, and finally influences the temperature [45]. Some of the key works demonstrating the sensitivity of climate to land surface albedo were performed by Charney et al. [29]. Without regard to the influence of the advection process, the increase will lead to the decrease of the solar radiation absorbed by the land surface, increase of the land surface temperature, subsequently increase of the long-wave radiation into the space and decrease the sensible heat and latent heat, and lead to the potential to decrease the temperature, and vice versa [45]. The lower land surface albedo indicates the lower reflectivity and higher shortwave absorption of the land surface. Taking the forest coverage as an example, its albedo is generally lower than that of the nudation and other vegetation types [46]. The historical deforestation in the middle-latitude zone led to the increase of the land surface albedo, which is especially remarkable after snowfall in the winter and might have made the northern hemisphere colder [4].

The leaf area index is an important indicator that represents the canopy structure and productivity of the plant community. It directly influences the ability of the plant to acquire and utilize the solar energy and indirectly influences the canopy impedance ratio. Besides, being an important parameter of the land surface albedo, it also directly influences the interaction between the land surface and the atmosphere [47]. More recent studies have focused on the role of the leaf area index in influencing the climate. The relevant researches indicate that the leaf area index is closely related to the precipitation, temperature, specific humidity, and so forth [48].

The significance of roughness has also been well realized [49]. The land surface roughness has impacts on the turbulent flow between the land surface and the atmosphere and subsequently influences the local diffusion flux. If the diffusion flux is higher, it will reduce the near-surface air temperature under the condition of no other feedback mechanisms [25]. The deforestation will decrease the land surface roughness and reduce the turbulent flow and will consequently increase the temperature in theory. However, the less turbulent flow will lead to the decrease of the heat and moisture transfer, which will increase the temperature and moisture gradients between the land surface and the atmosphere and in turn alleviate the warming effect [49]. Davin and de NobletDucoudre [41] analyzed the sensitivity to the roughness during the conversion of the forest to the grassland. Their result indicates that the change in the roughness will make the global temperature increase by $0.29^{\circ} \mathrm{C}$, and the increase will be even more obvious in the tropic zone.

2.2. Impacts on the Biogeochemical Process. The influence of the land use change on the biogeochemical process, especially the discharge or absorption of the greenhouse gases such as $\mathrm{CO}_{2}$ in the atmosphere due to the land use change, can alter the concentration of the greenhouse gases in the atmosphere and consequently influence the climate [13]. The historical accumulative carbon loss due to the land use change was estimated to be 180-200 $\mathrm{PgC}$ [50], and the land use change contributed to $10 \%-30 \%$ of the carbon discharge due to human activities. The deforestation, afforestation, forest restoration, and agricultural activities are the major approaches through which the land use influences the carbon cycle. There are many researches on the influence of the land use change on the carbon cycle, most of which focused on the deforestation, especially the deforestation in the tropic rainforest. Since the 1850s, the global forest area decreased by $20 \%$, and the carbon emission due to the deforestation accounted for $90 \%$ of the carbon emission caused by the land use change [51] and 33\% of the man-made carbon emission (including the discharge from the fossil fuel burning and land use change) [4].

The influence of the afforestation and forest restoration on the carbon cycle has also gradually become the hot issue in the relevant researches. Although the reforestation has not significantly influenced the terrestrial carbon sink on 
the global scale, it has played an important role in the carbon sink on the regional scale. For example, the man-made forests in China have stored over 0.45 Gt carbon since the 1970s [52]. Some researches indicated the forest restoration played a key role in the carbon sink resulting from the land use $[53,54]$.

The productivity of the forest and decomposition of organic matters in the soil both influence the change of $\mathrm{CO}_{2}$ in the atmosphere and the climate pattern and consequently influence the terrestrial carbon sink. When the photosynthesis rate is higher than the respiration rate, discharge rate of the biogenic volatile organic compounds (BVOC), and the decomposition rate of organic carbon, the forest plays a role as the carbon sink [55]. Besides, the deforestation will reduce the potential carbon sequestration [50]. In addition, the higher temperature and higher $\mathrm{CO}_{2}$ concentration will increase the NPP, which will lead to the negative feedback and make more $\mathrm{CO}_{2}$ in the atmosphere sequestrated. The radiative forcing due to the carbon emission resulting and the accelerated respiration due to the higher temperature will lead to the positive feedback, in which the organic matters will decompose more rapidly [56]. For example, there is an extreme example in the climate-carbon cycle; that is, the tropic rainforest in Amazon will gradually succeed into another vegetation if the temperature continuously increases and the precipitation continuously decreases.

The agricultural activities also have significant impacts on the carbon cycle. For example, the conversion of the natural vegetation to the cultivated land, loss of plant biomass, and increased decomposition of organic matters in the soil all make the agricultural activities become one of the major sources of $\mathrm{CO}_{2}$ emission. By contrast, the utilization of the high yield variety and fertilizers, irrigation, and no-till agriculture all contribute to the reduction of carbon loss and increase the absorption of carbon in the agricultural regions [56]. For example, the no-till agriculture in the USA has increased the organic content in the soil, reaching $1.4 \mathrm{Gt}$ carbon in the past 30 years. However, the increase of the organic matters in the soil can only last for 50-100 years, after which a new equilibrium of carbon cycle will be reached [57].

A lot of BVOCs are generated by the plants and then released into the atmosphere. These compounds have significant influence on the physical and chemical characteristics of the atmosphere due to their great amount [58]. Although the BVOCs have no direct influence on the radiation balance of the atmosphere, they affect the longevity of the methane in the atmosphere and play an important role in the formulation of the ozone and secondary organic aerosols (SOAs). The SOAs can directly influence the climate since they can scatter or absorb the solar radiation and consequently decrease or increase the temperature [59]. The overall influence of the SOAs on the climate system has not been accurately quantified so far; they may mainly play a role in decreasing the temperature [45]. The SOAs also have significant indirect impacts on the climate; that is, they may act as the cloud condensation nuclei $(\mathrm{CCN})$ in the formation of the clouds. In fact, the BVOCs released by the boreal forest have made the local CCN increase by $100 \%$ [59], which in turn influences the number of water drops in the cloud and makes the albedo of the atmosphere increase by $3 \%-8 \%$.
There will be an albedo difference ranging from $-1.8 \mathrm{~W} / \mathrm{m}^{2}$ to $-6.7 \mathrm{~W} / \mathrm{m}^{2}$ in the regions between $60^{\circ}$ and $90^{\circ} \mathrm{N}$ since the albedo increases due to the indirect influence of BVOC. This means that, owing to the feedback among BVOCs released by the trees, SOA, CNN, and land surface albedo, the boreal forest will make the local climate colder. The influence of BVOC on CCN is considered to be the most important in the boreal forest since the regional air pollution is slight [59]. In addition, the net emission of carbon released due to the deforestation depends on the land use type converted from the forest or the temporal scale of the regeneration of the forest and the feedback mechanism mentioned previously. According to the simulation which only takes into account the biogeochemical influence, the complete deforestation will make the global temperature increase by $0.09^{\circ} \mathrm{C}$ or $0.19^{\circ} \mathrm{C}$ if the forests between $50-60^{\circ} \mathrm{N}$ and $0-10^{\circ} \mathrm{S}$ were completely felled [45]. This is because of the great amount of biomass in the tropic zone and depends on the total biomass of different forest types.

The impacts of the LUCC on the regional temperature and precipitation are the synthetic effects of the processes mentioned previously. There has been great progress in the research on the single process and the synthetic effects. Besides, the impacts of the land cover change happen at certain temporal and spatial scales. For example, the mesoscale land cover change influences the regional temperature through the land surface albedo in short and medium terms, while the geochemical process influences the change in temperature at larger temporal and spatial scales.

\section{Simulation of the Effects of LUCC on the Regional Climate Model}

3.1. Development from the Global Climate Models to the Regional Climate Models. The climate model consists of the set of equations that can be used to determine the characteristics and evolution of the components of the climate system according to the fundamental physical laws such as the law of conservation of energy and law of conservation of mass. Then the climate model is constructed by routinizing the set of equations with the computer. The climate model can be used to not only simulate the current climate, but also to simulate the climate change caused by the change in the boundary conditions [60]. Therefore, the climate model will serve as the most important test tool if the people wish to study the climate and its change with the experimental method.

The earliest researches on the regional climate effects generally used the general circulation models (GCMs), and carried out the sensitivity test with the force-response method $[61,62]$, that is, represent the land use changes with the changes of the land surface parameters (e.g., albedo, roughness, and evapotranspiration). Generally, the control experiment is first carried out with the GCMs, and then the land surface parameters are changed to carry out the simulation and thereafter compare with the reference test so as to analyze the response of the climate to the land use changes [48]. Charney et al. [29] first applied this method in the study of the positive feedback mechanism between 
the land surface albedo and aridification in the Sahara Desert. Thereafter, the method was applied to many researches on the response of climate to the change of the land surface parameters such as the evapotranspiration [63], roughness [49], stomatal conductance [64], and leaf area index [65].

The GCMs have been widely used in the study of climate change, and a lot of effective work has been done in the simulation of influence of the LUCC on the global temperature and precipitation at large scale and the research on the climate effects of trace gases in the atmosphere and so forth $[13,66$, 67]. However, it is difficult to simulate the regional climate at small scales precisely with the GCMs due to the limitation of the resolution. Besides, the resolution is very low in the GCMs (above 100-200 km), so they cannot be used to describe the complex terrain and land surface characteristics. Therefore, there are some bias and uncertainties in the simulation of the regional climate change with the GCMs [68], which influences the credibility of the simulation result.

The regional climate model was proposed during the late 1980s and the early 1990s [69] and has become an important tool in the regional climate researches [70]. The regional climate model has higher resolution and can more reasonably simulate the regional forcing such as the terrain, rivers/lakes, and urban buildings and describe the detailed characteristics of the land surface. Besides, it can reflect the climate characteristics caused by the strong regional forcing [71], thus consequently having been widely used in the regional climate researches.

More attention has been paid to the response of regional and local climate to the land use change rather than that of the global climate. However, the resolution of the current climate models, for example, the global ocean-atmosphereland system with high complexity and the Earth system model of the moderate complexity, is generally too low when the model is used at the local and regional scales. In the recent decades, the high resolution regional climate models, for example, RegCM2, RegCM3, RAMS, RIEMS, RegCMNCC, and IPCR-RegCM, have been widely used in the research on the regional land use change. For example, these models have been applied to the desertification experiment [72], deforestation experiment in the tropic rainforest [73], vegetation restoration experiment [32], and so forth. Besides, some researchers analyze the impacts of land use change on the regional temperature and precipitation and so forth [7] and the influence of land use changes on the fundamental regional climate characteristics at the national scale $[48,74$, 75 ] by comparing the current land use data and the data of potential natural vegetation.

3.2. Research on the Integration of the Improved Land Surface Model and Regional Climate Model. Although some regional climate models have higher resolution (below $100 \mathrm{~km}$ ), there are still a lot of great challenges in the simulation of the land surface processes. For example, it is still necessary to represent the land surface process which is very important to the climate at the small scales, although there is little evidence that the simulation with climate models can provide reliable information at small scales $[76,77]$. Since the atmosphere and the land surface integrate into an inseparable whole system through the exchange of energy, dynamics and, moisture, it is the key to the successful simulation with the regional model to construct a land surface model that can accurately and precisely simulate the interaction between the atmosphere and the land surface.

By contrast with the regional climate model, the land surface model focuses more on the interaction between the atmosphere and the land surface and can calculate the exchange of energy, dynamics, and moisture between the land surface and the atmosphere. The scholars have gradually realized the importance of the land surface process in the climatology, geobiochemistry, weather forecasting, and so forth, since the 1970s. Since the middle 1980s, many researchers have studied the issue of deforestation in the tropical rainforest in the Amazon watershed and carried out a lot of sensitivity analyses [77-79]. Xue and Shukla [80] and Nicholson et al. $[38,81]$ also studied the desertification in the Sahara desert. All the sensitivity analyses from different perspectives suggest that the change of the boundary conditions of the land surface can lead to significant changes of the climate pattern. With the development of the land surface process model, more biophysical processes of vegetation were introduced. The researches constructed complex parameterization schemes of the exchange of radiation, moisture, energy, and dynamics above the vegetation, which can more realistically reflect the role of vegetation in the land surface process, especially the role of vegetation in the water budget and energy budget of the land surface.

Since the 1990s, the researches gradually considered the water-vapour absorption of vegetation and introduced the biochemical process that the vegetation absorbs $\mathrm{CO}_{2}$ for photosynthesis into the land surface model according to the relationship between the photosynthesis and plant water. There have been many improved land surface models, for example, the land surface model (LSM), improved simple biosphere model (SiB2) [82], community land model (CLM) [83]. These improved land surface models have a better ability to simulate the carbon flux and daily and seasonal cycle of $\mathrm{CO}_{2}$ concentration and can be used to simulate the enhanced greenhouse effect due to the increase of $\mathrm{CO}_{2}$ concentration in the atmosphere. The latest land surface models focus more on the biogeochemical process. For example, Niyogi et al. [84] represented the transpiration of vegetation with the Jarvistype stomatal resistance and coupled the photosynthesis with a mesoscale numerical forecast model; the improved model could effectively reflect the different characteristics of land surface, for example, the soil moisture and leaf area index.

With the continuous development of the regional climate model, a great number of researchers have applied the coupled regional land surface model to the study of various physical processes and their impacts on the regional climate, energy budget, and interactions between the land surface and the atmosphere $[85,86]$. The relevant researches mainly focused on the schemes of the soil-vegetation-atmosphere interaction. For example, Bonan et al. [83] integrated the CLM and community climate model (CCM), studied the phenological characteristics of land surface and analyzed the biomass flux. Besides, Dai et al. [87] developed the common 
land model (CoLM) by taking the advantage of the land surface, models such as LSM, which took into account the heterogeneity of the land surface characteristics within the grids, ecological difference of various vegetation types, and variation in the hydraulic characteristics and thermodynamic characteristics of different soil types, and consequently had a good ability to simulate the interaction between the land surface and the atmosphere.

\section{Application of the Regional Climate Model}

4.1. Agricultural Land Development and Management. As a result of this enormous growth in population and technology, the total global area of cropland almost doubled every century after AD 1600 from 3.0 million $\mathrm{km}^{2}$ in $\mathrm{AD} 1700$ to 4.2 million $\mathrm{km}^{2}$ in $\mathrm{AD} 1800,8.5$ million $\mathrm{km}^{2}$ in $\mathrm{AD} 1900$, and 15.3 million $\mathrm{km}^{2}$ in AD 2000 [88]. More attention has been paid to the influence of the management of the farmland on the climate, for example, the irrigation, no-till agriculture, and crop rotation, among which the influence of irrigation received the most attention. The change in irrigation has been expected to influence the local climate since it directly influences the soil moisture, which will further affect the land surface albedo, evaporation and variation in the regional temperature and precipitation [89]. The irrigation area has increased very rapidly during the past centuries. For example, the global irrigation area was 8.0 million hectares (Mha) in 1800 , and it increased to $40 \mathrm{Mha}$ in 1900 and further increased 2.7 Mha in 2000 [90]. The global irrigation water accounts for $70 \%$ of the water used by human beings [91]. The irrigation districts mainly include China, India, Pakistan, Thailand, North America, and the Aral Sea watershed [90].

There have been very few quantitative studies of how the climate responds to irrigation. The simulation studies in many regions indicated that the increased soil moisture due to irrigation will generally lead to significant decrease of the local average and maximum temperature $\left(T_{\max }\right)$, while the change of the minimum temperatures $\left(T_{\min }\right)$ varies among regions [92]. The irrigation will make the regional moisture in the atmosphere increase significantly, and consequently may make the regional precipitation increase under the appropriate weather conditions [91]. Besides, the irrigation play a role in reducing the regional temperature [75, 92-95] and the daily temperature difference [95].

The irrigation mainly influences the regional temperature by the following approach. The irrigation mainly influences the climate through the redistribution of the latent heat and sensible heat. When the irrigation area increases, the latent heat will increase while the sensible heat will decrease. The increase of latent heat will further lead to the increase of cloud coverage and decrease of the net radiation of land surface. The researches have indicated that there are obvious seasonal variations of the temperature decrease due to the irrigation. The temperature will reduce significantly in the dry season and insignificantly in the rainy season [94, 95]. Besides, there is an obvious regional heterogeneity of the temperature decrease due to the irrigation [95]. The simulation researches indicated that the difference in the irrigation area will lead to the difference in soil moisture. The difference in the response of the cloud to the irrigation is the main reason for the difference in the regional climate. The cooling effect of irrigation in some regions (e.g., North America, northwest part of India, northeast part of China) is comparable to the warming effect in the magnitude and consequently plays a role in alleviating the climate warming [90]. However, according to the prediction of the land use changes, the irrigation area in these regions will show a decreasing trend in the future decades, which will aggravate the climate warming.

\subsection{Urbanization and Its Regional Climate Effect. Urbaniza-} tion is an extreme way in which the human activities alter the underlying surface properties and influence the local climate. The urban heat island effect due to urbanization is an extreme example of the influence of LUCC on the regional climate [96]. The urbanization has contributed to $50 \%$ of the increase of land surface temperature in the USA since 1950 [97]. The city differs greatly from the natural land cover. The widespread impervious surface and the roof and wall of buildings and so forth, in the cities all influence the energy flux, and circulation of water and other materials [98]. They can reduce the evaporation from land surface, make it difficult to eliminate the land surface heat, and consequently lead to the increase of land surface temperature $[99,100]$. Besides, the man-made heat emission and decrease of vegetation coverage also contribute to the increase of land surface temperature. In some cities, the local people have grown a lot of plants or painted the roofs white so as to reduce the reflectivity of the urban land surface and alleviate the urban heat island effect $[17,101]$.

Considerable progress has been made in the development of urban climate models which are able to predict/simulate meteorological conditions from regional to building scales. Oleson et al. [102] designed a preliminary parameterization scheme of the city by integrating the CLM and applied it in the off-line simulation, the result of which indicated that the heat storage capacity and sensible heat flux are very sensitive to the uncertainties of the parameters of the atmosphere and land surface. The results of current qualitative researches indicate that the lowest daily air temperature increases more than the highest daily air temperature, which leads to the decrease of the daily temperature difference $[103,104]$. Besides, the Bowen ratio and canopy temperature of cities will increase with the proportion of impervious surface [105]. In addition, previous researches have mainly focused on the urban heat island effect of the big cities. For example, the research of Ezber et al. [106] indicated that the velocity of the prevailing northeasterly wind and the water vapor mixing ratio in Istanbul both reduced, and the heating effect due to urbanization penetrated into about $600-800 \mathrm{~m}$ height over the city in the atmosphere. Besides, Trusilova et al. [107] investigated the effects of urban land on the climate in Europe in January and July of 6 years (2000-2005) based on the MM5 model. Bohnenstengel et al. [108] present simulations of London's meteorology using the Met Office Unified Model and point out that urban land use fraction is the dominant control on 
the spatial structure in the sensible heat flux and the resulting urban increment.

The researches on the urban heat island effect with different models may get very different and even opposite results becouse the urbanization process is very complicated and many factors may influence it. Several sensitivity studies of the urban effects (urban albedo and roughness, anthropogenic heat flux, heat island, and urban aerosols) on meteorology and air pollution at different scales had been done. For example, Zhang et al. [109] conducted a numerical simulation for two heavy summer rainfall events in Beijing under different urban land use scenarios with a mesoscale MM5 model. The results of their simulation showed that the urban expansion leads to higher surface temperature, less evaporation and more mixture of water vapor in the boundary layer, and consequently there will be less convective available potential energy and the precipitation will decrease in most part of Beijing, especially in the Miyun reservoir area. Besides, Miao et al. [110] conducted a simulation to test a case study of heavy rainfall to different urban processes with the Weather Research and Forecasting (WRF) model. However, the results of their simulation showed that when the urbanization level increases, the urban heat island effect will become stronger, which may enhance the convection and consequently increase the maximum and accumulated amount of precipitation. Future studies that utilize a wide range of scenarios for climate, land use, and realistic urban parameters to quantify the effects of different factors on regional climate are needed.

\section{Concluding Remarks}

This paper reviewed the advances in the researches on the influence of the LUCC on the regional climate, including how the LUCC influences the regional climate, the relevant simulations and their improvement, and the application in case studies; the main findings can be summarized as follows. A large number of researches have documented the important effects of the LUCC on the regional climate system. Besides, the biogeophysical and biogeochemical effects of large-scale LUCC have also been studied. But the relevant researches on their mechanism have generally studied the biogeophysical and biogeochemical effects separately. It is the main means of the research on the effects of land use changes on the climate to carry out numerical simulation with a series of climate models of different complexities. The regional climate models have higher resolution and can reflect the climatic characteristics caused by the local forcing and have been widely used in the research on some representative land use changes, for example, the deforestation in the tropic zone, desertification, irrigation of the cultivated land, and urbanization.

Although there have been many consentaneous conclusions in many aspects of the current researches, there is still great uncertainty in the simulation of effects of the LUCC on the regional climate. First, the climate system contains multiscale dynamics and interactions between multiple weather systems. Second, there is great variation in the influence of the land use changes in different regions on the climate system. Therefore, in order to reduce the uncertainty in these relevant researches, on the one hand, it is necessary to precisely examine and depict the parameters of LUCC and other parameters of the land surface, which depends on the development of the remote sensing techniques. On the other hand, it is still necessary to strengthen the research on the land surface process. It not only requires the mathematicalphysical models that can effectively simulate the interaction between the land surface and the atmosphere, but also needs to improve the observation techniques so as to understand the essence of the land surface process and provide the reasonable initial value parameters for the mathematicalphysical models.

The urbanization has significant influence on the local climate, for example, the urban heat island effect due to the urbanization and the effects of the urban aerosol on the precipitation. However, since the area of the city is generally very small, it is difficult to parameterize the urban land surface due to its great complexity, and there have been no researches on the simulation of the process of urbanization in the regional climate models either. In fact, with the development of the society and economy, the urban population will continually increase and the urban area will further expand, and consequently the effects of urbanization on the climate will be more and more important. The assessment and prediction of the influence of urbanization will be one of the major directions in the relevant researches in the future.

As for the intersection between the researches on the land use changes and the climate change, the researches on the climate effects of the future land use changes mainly focus on two important issues. First, great efforts have been made to understand the climate effects of the past and current LUCC; however, there have been very few researches on that of the future LUCC. Second, how to predict the land use changes in the future and predict and assess its influence on the future climate may become a hot issue in the relevant research fields.

\section{Acknowledgments}

This research was financially supported by the National Key Programme for Developing Basic Science in China (Grant no. 2010CB950904), China National Natural Science Funds for Distinguished Young Scholar (Grant no. 71225005), and the Project of the National Natural Science Foundation of China (Grant no. 41071343).

\section{References}

[1] J. A. Foley, R. DeFries, G. P. Asner et al., "Global consequences of land use," Science, vol. 309, no. 5734, pp. 570-574, 2005.

[2] R. Pachauri and A. Reisinger, IPCC Fourth Assessment Report, Intergovernmental Panel on Climate Change (IPCC), Geneva, Switzerland, 2007.

[3] D. Ojima, Global Land Project: Science Plan and Implementation Strategy, IGBP Secretariat, 2005.

[4] J. J. Feddema, K. W. Oleson, G. B. Bonan et al., "Atmospheric science: the importance of land-cover change in simulating future climates," Science, vol. 310, no. 5754, pp. 1674-1678, 2005. 
[5] C. Fu, W. Dong, G. Wen, and D. Ye, "Regional response and adaptation to global change," Acta Meteolorogica Sinica, vol. 61, no. 2, pp. 245-249, 2003.

[6] G. B. Bonan, "Forests and climate change: forcings, feedbacks, and the climate benefits of forests," Science, vol. 320, no. 5882, pp. 1444-1449, 2008.

[7] L. M. Kueppers and M. A. Snyder, "Influence of irrigated agriculture on diurnal surface energy and water fluxes, surface climate, and atmospheric circulation in California," Climate Dynamics, vol. 38, no. 5-6, pp. 1017-1029, 2012.

[8] A. K. Betts, J. H. Ball, A. C. M. Beljaars, M. J. Miller, and P. A. Viterbo, "The land surface-atmosphere interaction: a review based on observational and global modeling perspectives," Journal of Geophysical Research D, vol. 101, no. 3, pp. 7209-7225, 1996.

[9] R. A. Pielke Sr. and D. Niyogi, "The role of landscape processes within the climate system," Lecture Notes in Earth Sciences, vol. 115, pp. 67-85, 2010.

[10] O. L. Phillips, L. E. Aragão, S. L. Lewis et al., "Drought sensitivity of the Amazon rainforest," Science, vol. 323, no. 5919, pp. 13441347, 2009.

[11] Z. M. Subin, W. J. Riley, J. Jin, D. S. Christianson, M. S. Torn, and L. M. Kueppers, "Ecosystem feedbacks to climate change in California: development, testing, and analysis using a coupled regional atmosphere and land surface model (WRF3-CLM3.5)," Earth Interactions, vol. 15, no. 15, pp. 1-38, 2011.

[12] M. Wang, X. Zhang, and X. Yan, "Modeling the climatic effects of urbanization in the Beijing-Tianjin-Hebei metropolitan area," in Theoretical and Applied Climatology, Springer, 2012.

[13] R. A. Pielke Sr., G. Marland, R. A. Betts et al., "The influence of land-use change and landscape dynamics on the climate system: relevance to climate-change policy beyond the radiative effect of greenhouse gases," Philosophical Transactions of the Royal Society A, vol. 360, no. 1797, pp. 1705-1719, 2002.

[14] R. A. Pielke Sr., J. Adegoke, A. Beltrán-Przekurat et al., "An overview of regional land-use and land-cover impacts on rainfall," Tellus B, vol. 59, no. 3, pp. 587-601, 2007.

[15] V. K. Arora and A. Montenegro, "Small temperature benefits provided by realistic afforestation efforts," Nature Geoscience, vol. 4, no. 8, pp. 514-518, 2011.

[16] A. M. Degu, F. Hossain, D. Niyogi et al., "The influence of large dams on surrounding climate and precipitation patterns," Geophysical Research Letters, vol. 38, no. 4, Article ID L04405, 7 pages, 2011.

[17] M. Wang, X. Yan, J. Liu, and X. Zhang, "The contribution of urbanization to recent extreme heat events and a potential mitigation strategy in the Beijing-Tianjin-Hebei metropolitan area," in Theoretical and Applied Climatology, 2013.

[18] A. T. Woldemichael, F. Hossain, R. Pielke, and A. BeltránPrzekurat, "Understanding the impact of dam-triggered land use/land cover change on the modification of extreme precipitation," Water Resources Research, vol. 48, no. 9, pp. 1-16, 2012.

[19] P. Meiyappan and A. K. Jain, "Three distinct global estimates of historical land-cover change and land-use conversions for over 200 years," Frontiers of Earth Science, vol. 6, no. 2, pp. 122-139, 2012.

[20] J. Pongratz, C. H. Reick, T. Raddatz, and M. Claussen, "Biogeophysical versus biogeochemical climate response to historical anthropogenic land cover change," Geophysical Research Letters, vol. 37, no. 8, Article ID L08702, 2010.
[21] P. Friedlingstein and I. C. Prentice, "Carbon-climate feedbacks: a review of model and observation based estimates," Current Opinion in Environmental Sustainability, vol. 2, no. 4, pp. 251257,2010

[22] P. A. Dirmeyer and J. Shukla, "Albedo as a modulator of climate response to tropical deforestation," Journal of Geophysical Research, vol. 99, no. 10, pp. 20-877, 1994.

[23] M. Georgescu, D. B. Lobell, and C. B. Field, "Direct climate effects of perennial bioenergy crops in the United States," Proceedings of the National Academy of Sciences of the United States of America, vol. 108, no. 11, pp. 4307-4312, 2011.

[24] J. Hansen, L. Nazarenko, R. Ruedy et al., "Climate Change: earth's energy imbalance: confirmation and implications," Science, vol. 308, no. 5727, pp. 1431-1435, 2005.

[25] S. Bathiany, M. Claussen, V. Brovkin, T. Raddatz, and V. Gayler, "Combined biogeophysical and biogeochemical effects of largescale forest cover changes in the MPI earth system model," Biogeosciences Discussions, vol. 7, no. 1, p. 387, 2010.

[26] J. Jin, S. Lu, S. Li, and N. L. Miller, "Impact of land use change on the local climate over the tibetan plateau," Advances in Meteorology, vol. 2010, Article ID 837480, 6 pages, 2010.

[27] F. H. Lambert, M. J. Webb, and M. M. Joshi, “The relationship between land-ocean surface temperature contrast and radiative forcing," Journal of Climate, vol. 24, no. 13, pp. 3239-3256, 2011.

[28] V. Brovkin, A. Ganopolski, M. Claussen, C. Kubatzki, and V. Petoukhov, "Modelling climate response to historical land cover change," Global Ecology and Biogeography, vol. 8, no. 6, pp. 509517, 1999.

[29] J. Charney, P. H. Stone, and W. J. Quirk, "Drought in the Sahara: a biogeophysical feedback mechanism," Science, vol. 187, no. 4175, pp. 434-435, 1975.

[30] J. Shukla and Y. Mintz, "Influence of land-surface evapotranspiration on the earth's climate," Science, vol. 215, no. 4539, pp. 1498-1501, 1982.

[31] E. F. Lambin and H. Geist, Land-Use and Land-Cover Change: Local Processes and Global Impacts, Springer, 2006.

[32] V. Brovkin, L. Boysen, T. Raddatz, V. Gayler, A. Loew, and M. Claussen, "Evaluation of vegetation cover and land-surface albedo in MPI-ESM CMIP5 simulations," Journal of Advances in Modeling Earth Systems, pp. 48-57, 2013.

[33] J. D. Wickham, T. G. Wade, and K. H. Riitters, "Comparison of cropland and forest surface temperatures across the conterminous United States," Agricultural and Forest Meteorology, vol. 166-167, pp. 137-143, 2012.

[34] J. D. Wickham, T. G. Wade, and K. H. Riitters, "Empirical analysis of the influence of forest extent on annual and seasonal surface temperatures for the continental United States," Global Ecology and Biogeography, vol. 22, no. 5, pp. 620-629, 2013.

[35] J. Shukla, C. Nobre, and P. Sellers, "Amazon deforestation and climate change," Science, vol. 247, no. 4948, pp. 1322-1325, 1990.

[36] Y. Malhi, J. T. Roberts, R. A. Betts, T. J. Killeen, W. Li, and C. A. Nobre, "Climate change, deforestation, and the fate of the Amazon," Science, vol. 319, no. 5860, pp. 169-172, 2008.

[37] L. Salvati and S. Bajocco, "Land sensitivity to desertification across Italy: past, present, and future," Applied Geography, vol. 31, no. 1, pp. 223-231, 2011.

[38] S. E. Nicholson, C. J. Tucker, and M. B. Ba, "Desertification, drought, and surface vegetation: an example from the west African sahel," Bulletin of the American Meteorological Society, vol. 79 , no. 5, pp. 815-829, 1998. 
[39] M. Zhao, A. J. Pitman, and T. Chase, "The impact of land cover change on the atmospheric circulation," Climate Dynamics, vol. 17, no. 5-6, pp. 467-477, 2001.

[40] M. Claussen, V. Brovkin, and A. Ganopolski, "Biophysical versus biogeochemical feedbacks of large-scale land cover change," Geophysical Research Letters, vol. 28, no. 6, pp. 1011-1014, 2001.

[41] E. L. Davin and N. de Noblet-Ducoudre, "Climatic impact of global-scale Deforestation: radiative versus nonradiative processes," Journal of Climate, vol. 23, no. 1, pp. 97-112, 2010.

[42] R. S. Defries, L. Bounoua, and G. J. Collatz, "Human modification of the landscape and surface climate in the next fifty years," Global Change Biology, vol. 8, no. 5, pp. 438-458, 2002.

[43] A. E. Dessler, "A determination of the cloud feedback from climate variations over the past decade," Science, vol. 330, no. 6010, pp. 1523-1527, 2010.

[44] A. H. Lynch, F. S. Chapin III, L. D. Hinzman et al., "Surface energy balance on the arctic tundra: measurements and models," Journal of Climate, vol. 12, no. 8, pp. 2585-2606, 1999.

[45] F.-S. Chapin III, M. Sturm, M. C. Serreze et al., "Role of landsurface changes in arctic summer warming," Science, vol. 310, no. 5748, pp. 657-660, 2005.

[46] C. J. Houldcroft, W. M. F. Grey, M. Barnsley, C. M. Taylor, S. O. Los, and P. R. J. North, "New vegetation Albedo parameters and global fields of soil background Albedo derived from MODIS for use in a climate model," Journal of Hydrometeorology, vol. 10, no. 1, pp. 183-198, 2009.

[47] G. B. Bonan and D. Pollard, "vegetation on global climate," Nature, vol. 359, 22 pages, 1992.

[48] J. H. Copeland, R. A. Pielke, and T. G. F. Kittel, "Potential climatic impacts of vegetation change: a regional modeling study," Journal of Geophysical Research D, vol. 101, no. 3, pp. 7409-7418, 1996.

[49] Y. Sud, J. Shukla, and Y. Mintz, "Influence of land surface roughness on atmospheric circulation and precipitation-a sensitivity study with a general circulation model," Journal of Applied Meteorology, vol. 27, no. 9, pp. 1036-1054, 1988.

[50] J. I. House, I. C. Prentice, and C. C. Le Quéré, "Maximum impacts of future reforestation or deforestation on atmospheric $\mathrm{CO}_{2}$," Global Change Biology, vol. 8, no. 11, pp. 1047-1052, 2002.

[51] R. A. Houghton and J. L. Hackler, "Sources and sinks of carbon from land-use change in China," Global Biogeochemical Cycles, vol. 17, no. 2, 1034 pages, 2003.

[52] J. Fang, A. Chen, C. Peng, S. Zhao, and L. Ci, "Changes in forest biomass carbon storage in China between 1949 and 1998," Science, vol. 292, no. 5525, pp. 2320-2322, 2001.

[53] S. W. Pacala, G. C. Hurtt, D. Baker et al., "Consistent land- and atmosphere-based U.S. Carbon sink estimates," Science, vol. 292, no. 5525, pp. 2316-2320, 2001.

[54] G. C. Hurtt, S. W. Pacala, P. R. Moorcroft et al., "Projecting the future of the U.S. Carbon sink," Proceedings of the National Academy of Sciences of the United States of America, vol. 99, no. 3, pp. 1389-1394, 2002.

[55] M. Heimann and M. Reichstein, "Terrestrial ecosystem carbon dynamics and climate feedbacks," Nature, vol. 451, no. 7176, pp. 289-292, 2008.

[56] P. Friedlingstein, P. Cox, R. Betts et al., "Climate-carbon cycle feedback analysis: results from the C4MIP model intercomparison," Journal of Climate, vol. 19, no. 14, pp. 3337-3353, 2006.

[57] P. Smith, D. S. Powlson, M. J. Glendining, and J. U. Smith, "Potential for carbon sequestration in European soils: preliminary estimates for five scenarios using results from long-term experiments," Global Change Biology, vol. 3, no. 1, pp. 67-79, 1997.

[58] J. Laothawornkitkul, J. E. Taylor, N. D. Paul, and C. N. Hewitt, "Biogenic volatile organic compounds in the Earth system: tansley review," New Phytologist, vol. 183, no. 1, pp. 27-51, 2009.

[59] D. V. Spracklen, B. Bonn, and K. S. Carslaw, "Boreal forests, aerosols and the impacts on clouds and climate," Philosophical Transactions of the Royal Society A, vol. 366, no. 1885, pp. 46134626, 2008.

[60] A. Kattenberg, F. Giorgi, H. Grassl et al., "Climate modelsprojections of future climate," in Climate Change 1995: The Science of Climate Change. Contribution of Working Group I to the Second Assessment Report of the Intergovernmental Panel on Climate Change, pp. 285-357, 1996.

[61] R. A. Pielke Sr., R. Avissar, M. Raupach, A. J. Dolman, X. Zeng, and A. S. Denning, "Interactions between the atmosphere and terrestrial ecosystems: influence on weather and climate," Global Change Biology, vol. 4, no. 5, pp. 461-475, 1998.

[62] I.-S. Kang, K. Jin, B. Wang et al., "Intercomparison of the climatological variations of Asian summer monsoon precipitation simulated by 10 GCMs," Climate Dynamics, vol. 19, no. 5-6, pp. 383-395, 2002.

[63] D. M. Lawrence, P. E. Thornton, K. W. Oleson, and G. B. Bonan, "The partitioning of evapotranspiration into transpiration, soil evaporation, and canopy evaporation in a GCM: impacts on land-atmosphere interaction," Journal of Hydrometeorology, vol. 8, no. 4, pp. 862-880, 2007.

[64] C. B. Field, R. B. Jackson, and H. A. Mooney, "Stomatal responses to increased $\mathrm{CO}_{2}$ : implications from the plant to the global scale," Plant, Cell and Environment, vol. 18, no. 10, pp. 1214-1225, 1995.

[65] T. N. Chase, R. A. Pielke, T. G. F. Kittel, R. Nemani, and S. W. Running, "Sensitivity of a general circulation model to global changes in leaf area index," Journal of Geophysical Research D, vol. 101, no. 3, pp. 7393-7408, 1996.

[66] R. A. Betts, "Biogeophysical impacts of land use on presentday climate: near-surface temperature change and radiative forcing," Atmospheric Science Letters, vol. 2, no. 1-4, pp. 39-51, 2001.

[67] H. Salmun and A. Molod, "Progress in modeling the impact of land cover change on the global climate," Progress in Physical Geography, vol. 30, no. 6, pp. 737-749, 2006.

[68] V. Brovkin, M. Claussen, E. Driesschaert et al., "Biogeophysical effects of historical land cover changes simulated by six Earth system models of intermediate complexity," Climate Dynamics, vol. 26, no. 6, pp. 587-600, 2006.

[69] H. Von Storch, E. Zorita, and U. Cubasch, "Downscaling of global climate change estimates to regional scales: an application to Iberian rainfall in wintertime," Journal of Climate, vol. 6, no. 6, pp. 1161-1171, 1993.

[70] J. Jin, N. L. Miller, and N. Schlegel, "Sensitivity study of four land surface schemes in the WRF model," Advances in Meteorology, vol. 2010, Article ID 167436, 11 pages, 2010.

[71] Y. Wang, L. R. Leung, J. L. McGregor et al., "Regional climate modeling: progress, challenges, and prospects," Journal of the Meteorological Society of Japan, vol. 82, no. 6, pp. 1599-1628, 2004.

[72] M. D. Oyama and C. A. Nobre, "Climatic consequences of a large-scale desertification in northeast Brazil: a GCM simulation study," Journal of Climate, vol. 17, no. 16, pp. 3203-3213, 2004 . 
[73] M. T. Coe, M. H. Costa, and B. S. Soares-Filho, "The influence of historical and potential future deforestation on the stream flow of the Amazon Rivervland surface processes and atmospheric feedbacks," Journal of Hydrology, vol. 369, no. 1-2, pp. 165-174, 2009.

[74] T. J. Stohlgren, T. N. Chase, R. A. Pielke Sr., T. G. F. Kittel, and J. S. Baron, "Evidence that local land use practices influence regional climate, vegetation, and stream flow patterns in adjacent natural areas," Global Change Biology, vol. 4, no. 5, pp. 495504, 1998.

[75] N. S. Diffenbaugh, "Influence of modern land cover on the climate of the United States," Climate Dynamics, vol. 33, no. 7-8, pp. 945-958, 2009.

[76] K. E. Trenberth, Climate System Modeling, Cambridge University Press, 1992.

[77] K. Mcguffie and A. Henderson-Sellers, A Climate Modelling Primer, Wiley, 2005.

[78] A. Henderson-Sellers, R. E. Dickinson, T. B. Durbidge, P. J. Kennedy, K. McGuffie, and A. J. Pitman, "Tropical deforestation: modeling local- to regional-scale climate change," Journal of Geophysical Research, vol. 98, no. 4, pp. 7289-7315, 1993.

[79] Y. Malhi, L. E. O. C. Aragão, D. Galbraith et al., "Exploring the likelihood and mechanism of a climate-change-induced dieback of the Amazon rainforest," Proceedings of the National Academy of Sciences of the United States of America, vol. 106, no. 49, pp. 20610-20615, 2009.

[80] Y. Xue and J. Shukla, "The influence of land surface properties on Sahel climate. Part I: desertification," Journal of Climate, vol. 6, no. 12, pp. 2232-2245, 1993.

[81] S. Nicholson, "Land surface processes and Sahel climate," Reviews of Geophysics, vol. 38, no. 1, pp. 117-139, 2000.

[82] P. J. Sellers, D. A. Randall, G. J. Collatz et al., "A revised land surface parameterization ( $\mathrm{SiB} 2$ ) for atmospheric GCMs. Part I: model formulation," Journal of Climate, vol. 9, no. 4, pp. 676705, 1996.

[83] G. B. Bonan, K. W. Oleson, M. Vertenstein et al., "The land surface climatology of the community land model coupled to the NCAR community climate model," Journal of Climate, vol. 15, no. 22, pp. 3123-3149, 2002.

[84] D. Niyogi, K. Alapaty, S. Raman, and F. Chen, "Development and evaluation of a coupled photosynthesis-based gas exchange evapotranspiration model (GEM) for mesoscale weather forecasting applications," Journal of Applied Meteorology and Climatology, vol. 48, no. 2, pp. 349-368, 2009.

[85] Y. Xue, F. J. Zeng, K. E. Mitchell, Z. Janjic, and E. Rogers, “The impact of land surface processes on simulations of the U.S. hydrological cycle: a case study of the 1993 flood usingthe SSiB land surface model in the NCEP Eta regional model," Monthly Weather Review, vol. 129, no. 12, pp. 2833-2860, 2001.

[86] Z. Yiqun, Q. Yongfu, M. Manqian, Y. Ge, K. Yushou, and Z. Donghua, "The effects of vegetation change on regional climate I: simulation results," Acta Meteorologica Sinica, vol. 60, no. 1, pp. 1-16, 2002.

[87] Y. Dai, X. Zeng, R. E. Dickinson et al., "The common land model," Bulletin of the American Meteorological Society, vol. 84, no. 8, pp. 1013-1023, 2003.

[88] K. Klein Goldewijk, A. Beusen, G. Van Drecht, and M. De Vos, "The HYDE 3.1 spatially explicit database of human-induced global land-use change over the past 12,000 years," Global Ecology and Biogeography, vol. 20, no. 1, pp. 73-86, 2011.

[89] P. Kabat, Vegetation, Water, Humans and the Climate: A New Perspective on an Interactive System, Springer, 2004.
[90] L. M. Kueppers, M. A. Snyder, and L. C. Sloan, "Irrigation cooling effect: regional climate forcing by land-use change," Geophysical Research Letters, vol. 34, no. 3, Article ID L03703, 5 pages, 2007.

[91] E. M. Douglas, A. Beltrán-Przekurat, D. Niyogi, R. A. Pielke Sr., and C. J. Vörösmarty, "The impact of agricultural intensification and irrigation on land-atmosphere interactions and Indian monsoon precipitation-a mesoscale modeling perspective," Global and Planetary Change, vol. 67, no. 1-2, pp. 117-128, 2009.

[92] L. M. Kueppers, M. A. Snyder, L. C. Sloan et al., "Seasonal temperature responses to land-use change in the western United States," Global and Planetary Change, vol. 60, no. 3-4, pp. 250264, 2008.

[93] D. B. Lobell and C. Bonfils, "The effect of irrigation on regional temperatures: a spatial and temporal analysis of trends in California, 1934-2002," Journal of Climate, vol. 21, no. 10, pp. 2063-2071, 2008.

[94] E. M. Douglas, D. Niyogi, S. Frolking et al., "Changes in moisture and energy fluxes due to agricultural land use and irrigation in the Indian Monsoon Belt," Geophysical Research Letters, vol. 33, no. 14, Article ID L14403, 5 pages, 2006.

[95] D. Lobell, G. Bala, A. Mirin, T. Phillips, R. Maxwell, and D. Rotman, "Regional differences in the influence of irrigation on climate," Journal of Climate, vol. 22, no. 8, pp. 2248-2255, 2009.

[96] J. M. Shepherd, "A review of current investigations of urbaninduced rainfall and recommendations for the future," Earth Interactions, vol. 9, no. 12, pp. 1-27, 2005.

[97] B. Stone Jr., "Land use as climate change mitigation," Environmental Science and Technology, vol. 43, no. 24, pp. 9052-9056, 2009.

[98] I. D. Stewart and T. R. Oke, "Local climate zones for urban temperature studies," Bulletin of the American Meteorological Society, vol. 93, no. 12, pp. 1879-1900, 2012.

[99] J. Li, C. Song, L. Cao, F. Zhu, X. Meng, and J. Wu, "Impacts of landscape structure on surface urban heat islands: a case study of Shanghai, China," Remote Sensing of Environment, vol. 115, no. 12, pp. 3249-3263, 2011.

[100] S. Kato and Y. Yamaguchi, "Estimation of storage heat flux in an urban area using ASTER data," Remote Sensing of Environment, vol. 110, no. 1, pp. 1-17, 2007.

[101] J. K. W. Wong and L. S. -K. Lau, "From the "urban heat island" to the vgreen island"? A preliminary investigation into the potential of retrofitting green roofs in Mongkok district of Hong Kong," Habitat International, vol. 39, pp. 25-35, 2013.

[102] K. W. Oleson, G. B. Bonan, J. Feddema, and M. Vertenstein, "An urban parameterization for a global climate model. Part II: sensitivity to input parameters and the simulated urban heat island in offline simulations," Journal of Applied Meteorology and Climatology, vol. 47, no. 4, pp. 1061-1076, 2008.

[103] A. Murata, H. Sasaki, M. Hanafusa, and K. Kurihara, "Estimation of urban heat island intensity using biases in surface air temperature simulated by a nonhydrostatic regional climate model," Theoretical and Applied Climatology, vol. 112, no. 1-2, pp. 351-361, 2013.

[104] K. Wang, H. Ye, F. Chen, Y. Xiong, and C. Wang, "Urbanization effect on the diurnal temperature range: different roles under solar dimming and brightening," Journal of Climate, vol. 25, no. 3, pp. 1022-1027, 2012.

[105] A. M. Coutts, J. Beringer, and N. J. Tapper, "Impact of increasing urban density on local climate: spatial and temporal variations in the surface energy balance in Melbourne, Australia," Journal 
of Applied Meteorology and Climatology, vol. 46, no. 4, pp. 477493, 2007.

[106] Y. Ezber, O. L. Sen, T. Kindap, and M. Karaca, "Climatic effects of urbanization in Istanbul: a statistical and modeling analysis," International Journal of Climatology, vol. 27, no. 5, pp. 667-679, 2007.

[107] K. Trusilova, M. Jung, G. Churkina, U. Karsten, M. Heimann, and M. Claussen, "Urbanization impacts on the climate in Europe: numerical experiments by the PSU-NCAR mesoscale model (MM5)," Journal of Applied Meteorology and Climatology, vol. 47, no. 5, pp. 1442-1455, 2008.

[108] S. I. Bohnenstengel, S. Evans, P. A. Clark, and S. E. Belcher, "Simulations of the London urban heat island," Quarterly Journal of the Royal Meteorological Society, vol. 137, no. 659, pp. 1625-1640, 2011.

[109] D.-L. Zhang, Y.-X. Shou, and R. R. Dickerson, "Upstream urbanization exacerbates urban heat island effects," Geophysical Research Letters, vol. 36, no. 24, Article ID L24401, 5 pages, 2009.

[110] S. Miao, F. Chen, Q. Li, and S. Fan, "Impacts of urban processes and urbanization on summer precipitation: a case study of heavy rainfall in Beijing on 1 August 2006," Journal of Applied Meteorology and Climatology, vol. 50, no. 4, pp. 806-825, 2011. 

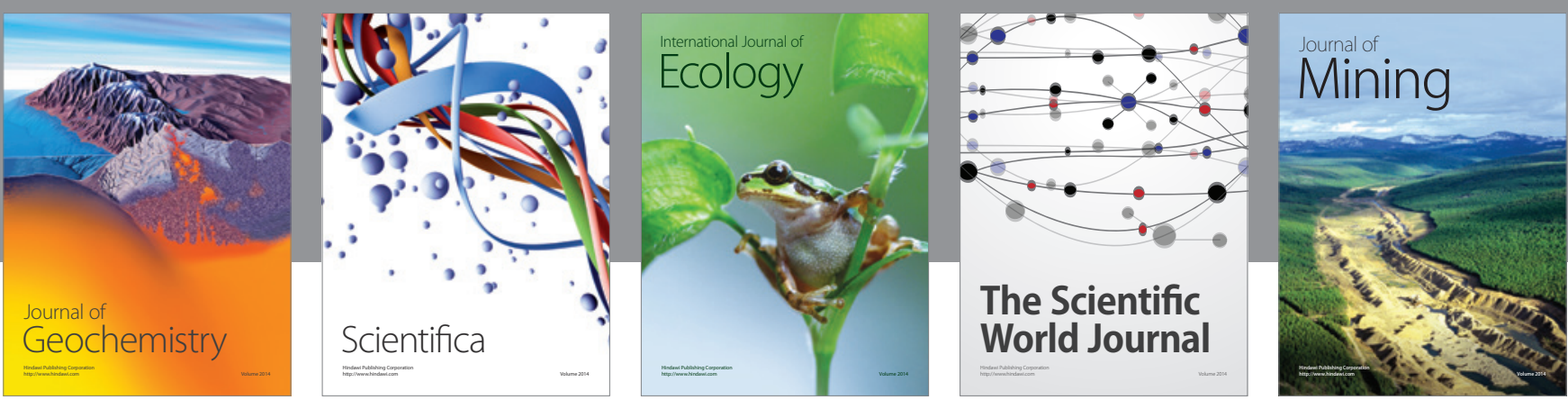

The Scientific World Journal
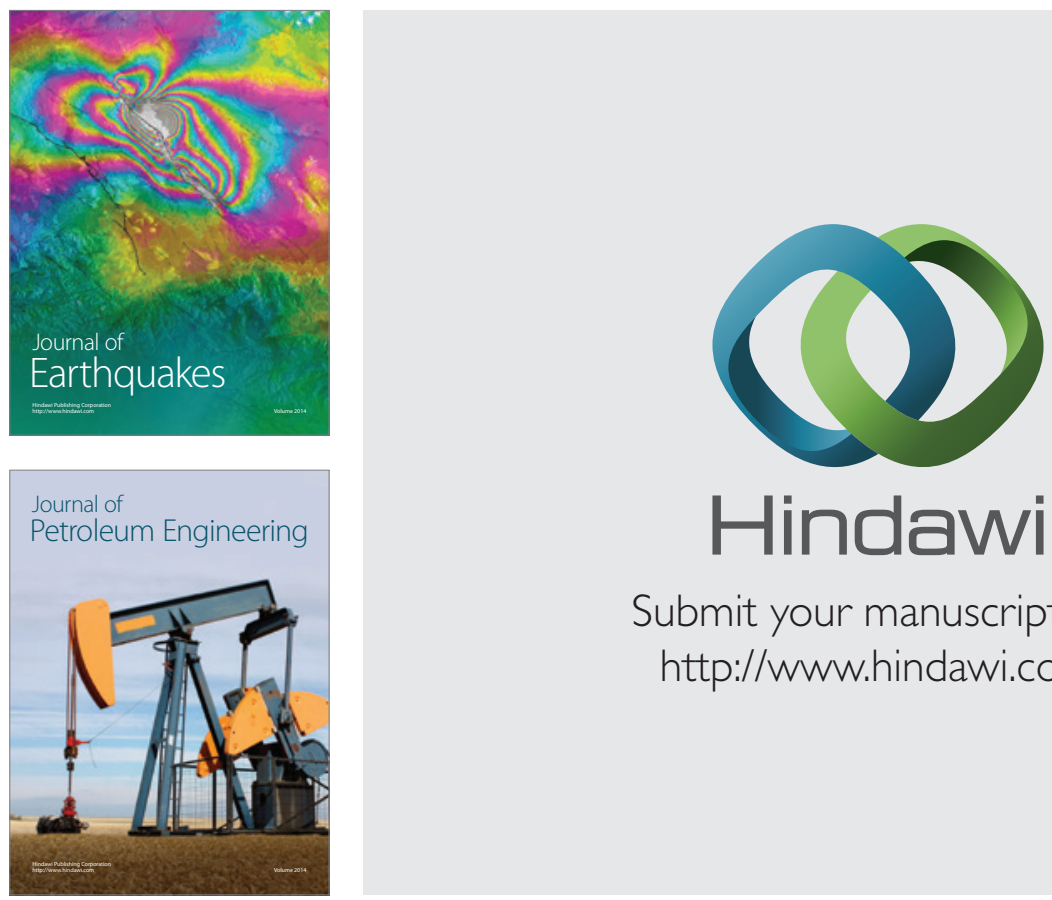

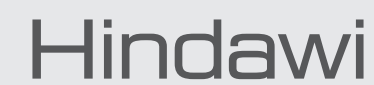

Submit your manuscripts at

http://www.hindawi.com
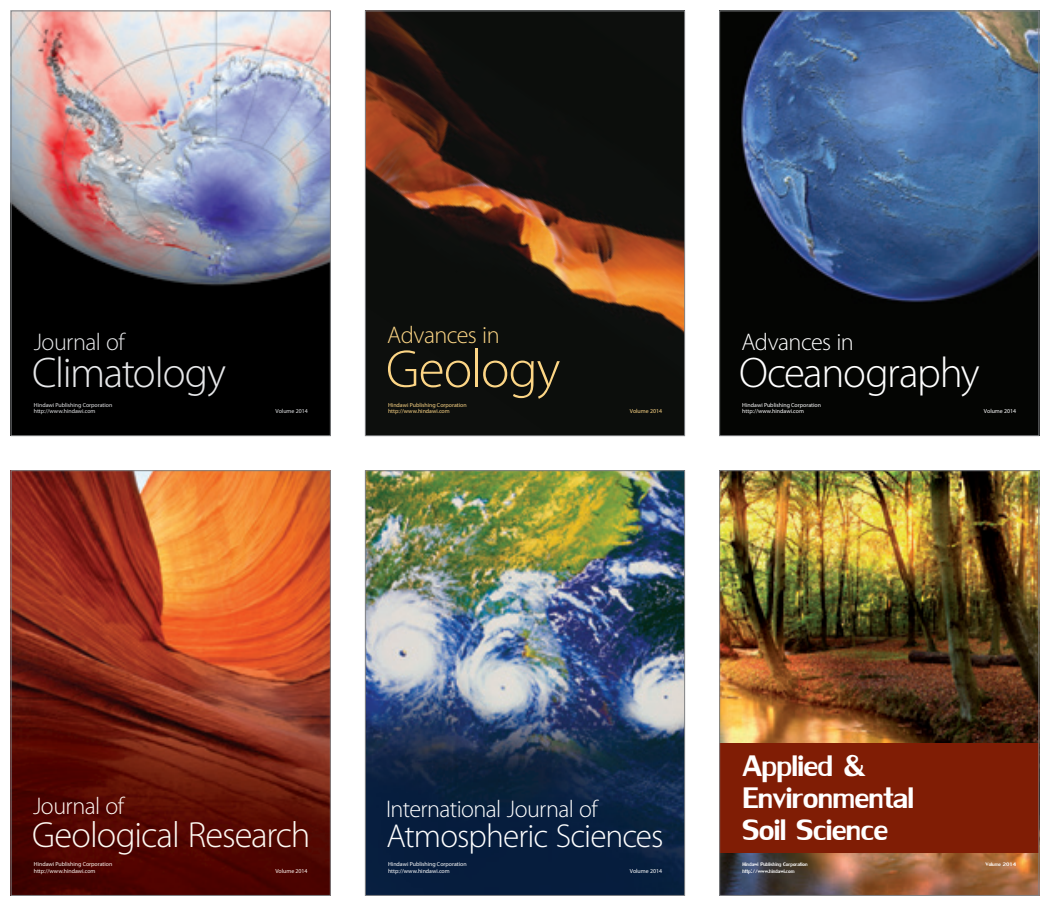
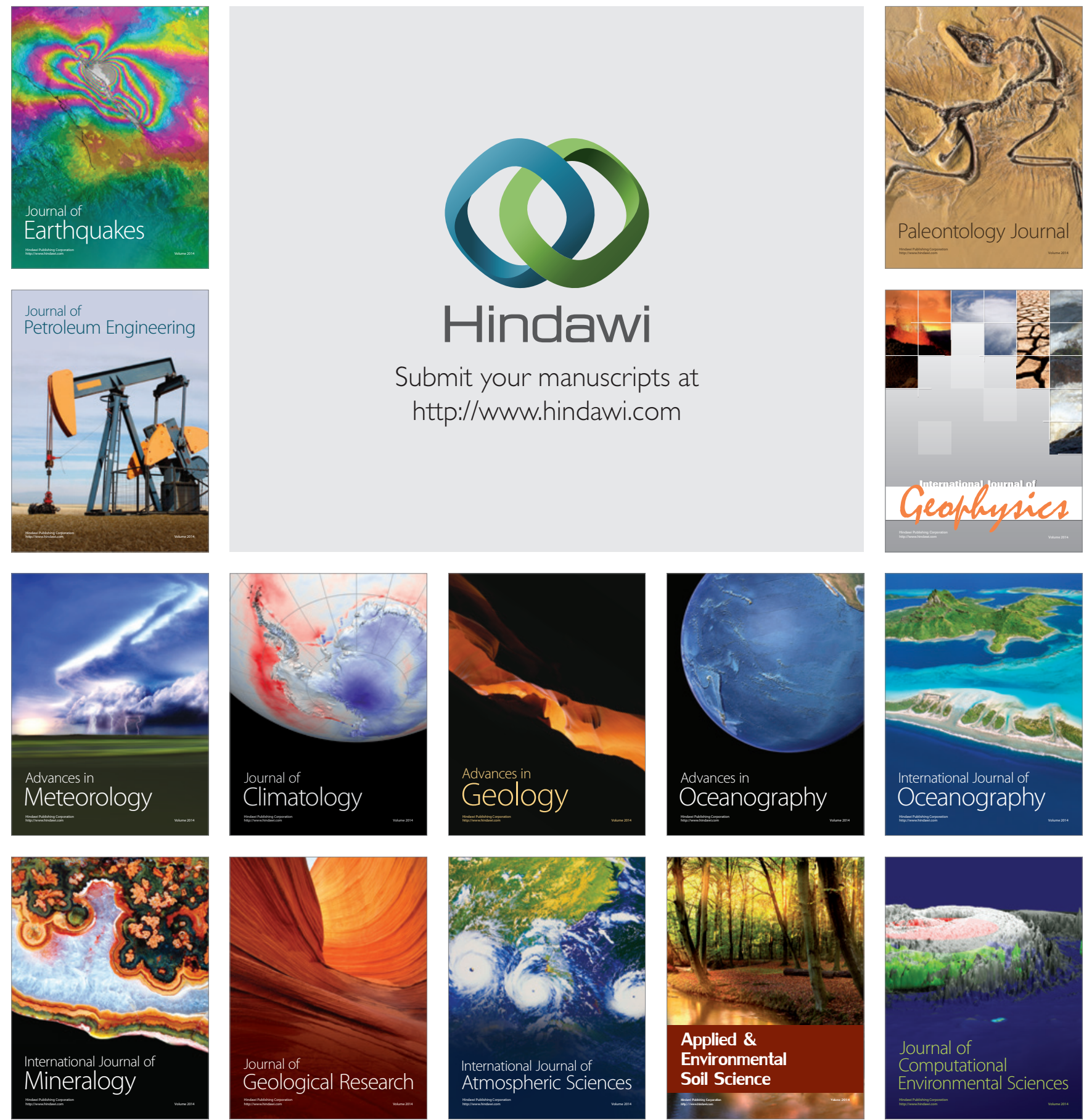